Research Article

\title{
Suitability Evaluation for Land Reclamation of Nonmetallic Mines in Xinjiang, China
}

\author{
Guobin Tang, Zizhao Zhang (D), Qianli Lv, Ruihua Hao, and Kaikai Wang \\ School of Geological and Mining Engineering, Xinjiang University, Urumqi, Xinjiang 830046, China \\ Correspondence should be addressed to Zizhao Zhang; 253569481@qq.com
}

Received 30 January 2020; Revised 20 March 2020; Accepted 13 April 2020; Published 5 May 2020

Academic Editor: Luis M. López-Ochoa

Copyright ( 2020 Guobin Tang et al. This is an open access article distributed under the Creative Commons Attribution License, which permits unrestricted use, distribution, and reproduction in any medium, provided the original work is properly cited.

\begin{abstract}
The ecological environment is fragile in Xinjiang, so it is necessary to carry out land reclamation for mines to restore its ecology. The premise of mines land reclamation is to determine the direction of land reclamation, which requires the suitability evaluation for land reclamation. In this paper, the evaluation index system and suitability evaluation model for land reclamation of nonmetallic mines in Xinjiang Uygur Autonomous Region were established. This model was established by using factor analysis, cluster analysis, and discriminant analysis and tested by back-substitution. First, using 149 units of 21 nonmetallic mines as research samples, the samples were divided into 4 categories by a combination of factor and cluster analysis. Then, the samples were trained using a discriminant analysis method to establish the corresponding land reclamation suitability evaluation model. This model was verified by back-substitution with an accuracy of $98.7 \%$, and only 2 of 149 samples were misclassified. Finally, the evaluation model was applied to the Dabancheng Toga Solo limestone mine in Urumqi. Evaluation analysis of 15 land reclamation units of this mine showed satisfactory results. The evaluation model developed here could serve as a powerful complement to the evaluation of land reclamation suitability in Xinjiang.
\end{abstract}

\section{Introduction}

Exploitation of mineral resources has always been the pillar industry of Xinjiang's economic development. Xinjiang is rich in nonmetallic mining resources, such as limestone, dolomite, marble, granite, jade, vermiculite ore, sand, and gravel $[1,2]$. Up to now, just the nonmetallic mining permits issued by the Land and Resources Department of Xinjiang Uygur Autonomous Region have amounted to more than 450 , with a combined area of over $650 \mathrm{~km}^{2}$. Nonmetallic mining methods are mainly open-pit mining (Figure 1), and large-scale mining is bound to severely damage the local ecological environment. Because the area of Xinjiang has an arid or semi-arid climate, the ecological environment is extremely fragile [3]. Land reclamation must be carried out after the pits are closed. An important prerequisite task and a specific challenge of land reclamation of nonmetallic mines in Xinjiang is to determine the direction of land types for land reclamation, that is, to evaluate the suitability results for land reclamation. Different land reclamation suitability evaluation results directly determine the future land reclamation measures [4]. It is necessary to establish an effective evaluation method for land reclamation evaluation of nonmetallic mines in Xinjiang.

In the past, many studies have produced fruitful results on the suitability evaluation of mining land reclamation using a variety of evaluation methods [5]. Previously established methods of evaluation mainly include the extremum value evaluation method [6-8], the GIS method [9-18], the discriminant analysis method used in the suitability analysis of coal mine reclamation [19], and the extension evaluation method [20]. Also the corresponding index system was established for evaluation [21, 22], fuzzy comprehensive evaluation method [23-25], clustering analysis methods [26], analytic hierarchy analysis [27, 28], evaluation using neural network models [29], and evaluation using spatial decision support systems [30]. However, the above evaluation methods were mostly aimed at the suitability evaluation of coal mines, and for specific evaluation areas. Because the land reclamation suitability evaluation 


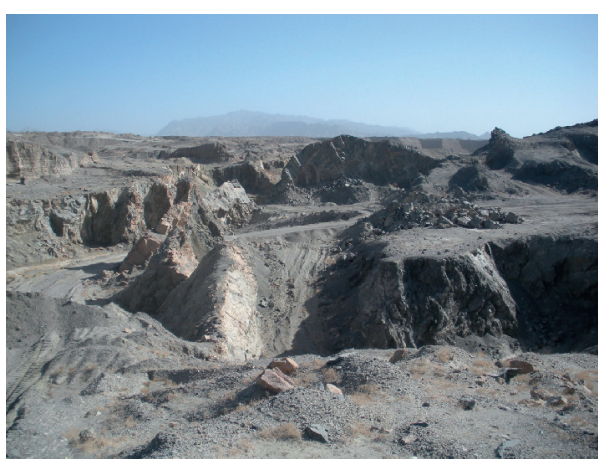

(a)

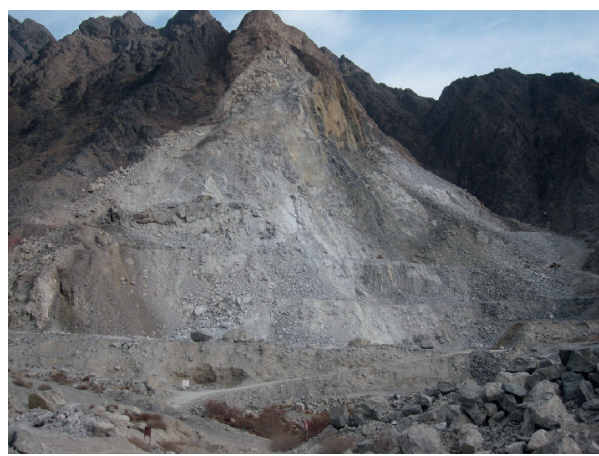

(c)

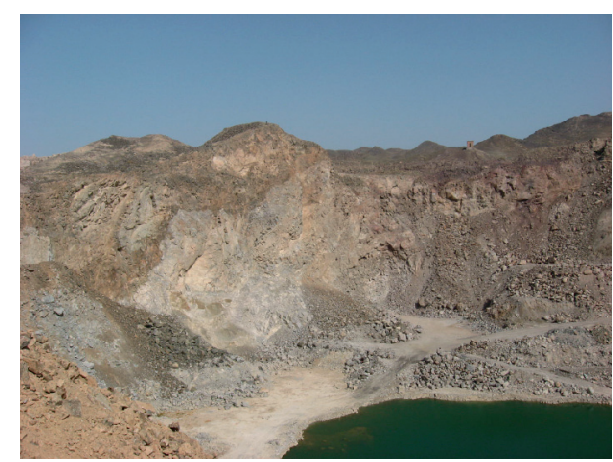

(b)

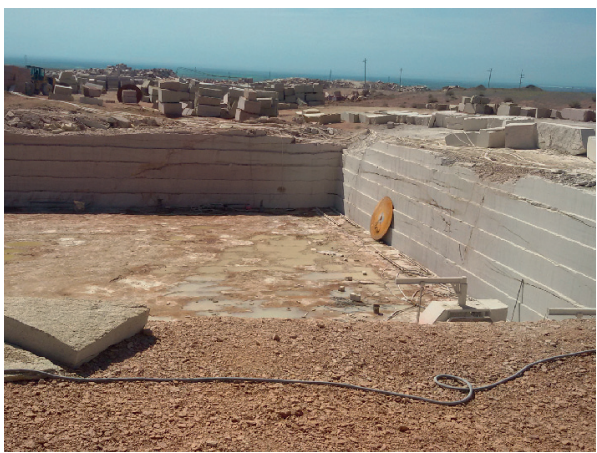

(d)

Figure 1: Open-pit mining for nonmetallic mines.

method of coal mines is mainly aimed at the land subsidence area formed by underground mining of coal mines, the way of land destruction is very different from that of nonmetallic mines, and the construction facilities of coal mines are also different from that of nonmetallic mines, so the above land reclamation suitability evaluation methods are obviously not suitable for the land reclamation work of nonmetallic mines. The evaluation indexes selected in the evaluation process are also different from place to place. To date, very few studies of land reclamation have taken into account the characteristics of damaged land in nonmetallic mines in Xinjiang and considered the special ecological environmental nature of the area.

At present, the suitability evaluation of mines land reclamation in Xinjiang is mainly carried out according to the relevant regulations and standards (Table 1) [31, 32]. Table 1 lists the results of the evaluation, which are categorized into four categories of very suitable (1), somewhat suitable (2), not very suitable (3), and unsuitable (4). The evaluation indexes include mainly four aspects: terrain slope, soil quality, irrigation and drainage conditions, and degree of pollution. Some indexes are difficult to quantify. The severity of land damage was inadequately considered, and the same evaluation indexes level may lead to two different results. For example, as shown in Table 1, for a reclamation unit with a terrain slope greater than $35^{\circ}$, the current land reclamation suitability evaluation grade would be "not very suitable" or "unsuitable" for reclamation as grassland. Such an evaluation result cannot determine in the first place whether the land reclamation unit is suitable or unsuitable for reclamation as grassland, and hence impossible to determine the land reclamation method and the reclamation workload. If it is unsuitable for reclamation as grassland, the land reclamation direction of this unit is bare land. A final land reclamation plan is only possible based on expert evaluation of the original land type, land use plan, and actual mine conditions.

In view of the above-mentioned research status and shortcomings of land reclamation suitability evaluation, we made a comprehensive study of the characteristics of damaged land and the ecological environmental conditions of nonmetallic mines in Xinjiang and determined the corresponding land reclamation suitability evaluation indexes system which is different from the previous research results according to relevant regulations and standards. The 21 nonmetallic mines are divided into 149 units according to the characteristics of land damage (e.g., the depth of pit excavation). The 149 land reclamation units were divided into four categories using combined cluster analysis method and classification factors without prior knowledge of specific classification results. Based on the accurate classification, a discriminant model was established for suitability evaluation of nonmetallic mines reclamation in Xinjiang. The land reclamation suitability evaluation model established in this paper could determine the land reclamation direction of land reclamation units for nonmetallic mines in Xinjiang at the first time, which is conducive to guiding land reclamation work. The evaluation model can be widely applied to the land reclamation of nonmetallic mines in Xinjiang. 
TABLE 1: Evaluation indexes and grading of land reclamation for Xinjiang mines.

\begin{tabular}{|c|c|c|c|c|}
\hline \multicolumn{2}{|c|}{ Limiting factors and analysis indexes } & \multirow{2}{*}{$\begin{array}{l}\text { Grading of land } \\
\text { reclaimed as farmland } \\
1\end{array}$} & \multirow{2}{*}{$\begin{array}{c}\text { Grading of land } \\
\text { reclaimed as forest } \\
\text { land }\end{array}$} & \multirow{2}{*}{$\begin{array}{c}\begin{array}{c}\text { Grading of land } \\
\text { reclaimed as } \\
\text { grassland }\end{array} \\
1\end{array}$} \\
\hline \multirow{6}{*}{ Topological slope } & $<3$ & & & \\
\hline & $4 \sim 7$ & 2 & 1 & 1 \\
\hline & $8 \sim 15$ & 3 & 1 & 1 \\
\hline & $16 \sim 25$ & 4 & 2 or 1 & 2 \\
\hline & $26 \sim 35$ & 4 & 2 & 3 \\
\hline & $>35$ & 4 & 3 or 2 & 4 or 3 \\
\hline \multirow{4}{*}{ Soil parent materials } & Loam & 1 & Little influence & Little influence \\
\hline & Clay and sandy loam & 2 & Little influence & Little influence \\
\hline & Sandy soil & 3 & Little influence & Little influence \\
\hline & Sandy-gravel soil & 4 & 4 or 3 & Little influence \\
\hline \multirow{5}{*}{$\begin{array}{l}\text { Thickness of cover } \\
\text { soils }(\mathrm{mm})\end{array}$} & $\geq 100$ & 1 & 1 & Little influence \\
\hline & $99 \sim 50$ & 2 & 1 & Little influence \\
\hline & $49 \sim 30$ & 3 & 2 or 3 & Little influence \\
\hline & $29 \sim 10$ & 4 & 2 or 4 & Little influence \\
\hline & $<10$ & 4 & 4 & 3or 4 \\
\hline \multirow{5}{*}{$\begin{array}{l}\text { Irrigation and } \\
\text { drainage condition }\end{array}$} & Unsubmerged or occasionally & & & \\
\hline & $\begin{array}{c}\text { submerged, with favorable irrigation and } \\
\text { drainage }\end{array}$ & 1 & 1 & 1 \\
\hline & $\begin{array}{l}\text { Seasonally submerged for a short time, } \\
\text { with moderate irrigation and drainage }\end{array}$ & 2 & 2 & 2 \\
\hline & $\begin{array}{l}\text { Seasonally submerged for a long time, } \\
\text { with poor irrigation and drainage }\end{array}$ & 3 & 3 & 3 or 4 \\
\hline & $\begin{array}{l}\text { Submerged for a long time, with almost } \\
\text { no irrigation and drainage }\end{array}$ & 4 & 4 & 4 \\
\hline \multirow{4}{*}{$\begin{array}{l}\text { Nonuniform } \\
\text { settlement }\end{array}$} & No settlement & 1 & 1 & 1 \\
\hline & Mild settlement & 2 or 3 & 1 & 2 \\
\hline & Moderate settlement & 4 & 2 or 3 & 3 \\
\hline & Severe settlement & 4 & 3 & 3 \\
\hline \multirow{4}{*}{ Degree of pollution } & No pollution & 1 & 1 & 1 \\
\hline & Mild pollution & 2 or 3 & 1 & 2 \\
\hline & Moderate pollution & 4 & 2 & 2 \\
\hline & Severe pollution & 4 & 3 & 3 \\
\hline \multirow{3}{*}{$\begin{array}{l}\text { Organic matter } \\
\text { content in soil }(\%)\end{array}$} & $>10$ & 1 & 1 & 1 \\
\hline & $10-6$ & 2 or 3 & 1 & 1 \\
\hline & $<6$ & 3 or 4 & 2 or 3 & 3 or 4 \\
\hline
\end{tabular}

This table is derived from actual land reclamation carried out for mines in Xinjiang and the relevant national standards (completion standards on land reclamation quality). 1 denotes very suitable for land reclamation; 2 denotes somewhat suitable for land reclamation; 3 denotes not very suitable for land reclamation; and 4 denotes unsuitable for land reclamation.

\section{Suitability Evaluation Indexes System of Mines Land Reclamation}

The types of land damaged by nonmetallic mines in Xinjiang are mainly grassland and bare land. This land reclamation suitability evaluation is also aimed at grassland reclamation. A system of indexes in which the indexes are both mutually independent and complementary was constructed for evaluating the suitability of land reclamation. The indexes chosen in this study consider mainly the following factors: first, measurability; that is, the indexes contributing to the evaluation must be measurable and numerically quantifiable. Second, dominant; that is, the increase and decrease of the indexes affect the rise and fall of the quality of the land reclamation units. Third, nonoverlapping; that is, the boundaries between the evaluating indexes are clear and do not overlap. Given the above requirements, considerations were given to the unique geographical characteristics of land damaged by nonmetallic mines in Xinjiang. Combined with relevant standards and characteristics of nonmetallic mines in Xinjiang, the selection of evaluation indexes was focused mainly on four major aspects: the severity of land damage, the soil conditions, the original vegetation conditions of the land reclamation units, and the irrigation and drainage conditions. These are described as follows:

(1) The severity of land damage includes the following aspects: (a) the dominant slope of the surface after excavation or the deposition of debris, which is denoted as $X_{1}$. This refers to the post-excavation dominant slope or the post-deposit dominant slope of the land. The greater the slope is, the more severe the damage to the land is. (b) The depth of the excavation $(\mathrm{m})$ or the flatness of the deposited debris 
$\left(\mathrm{m}^{3} / \mathrm{m}^{2}\right)$, which is denoted as $X_{2}$. This refers to the dominant depth of the ground relative to the surrounding ground after the excavation or the amount of leveling per unit area of the land after deposit. The greater the value of this index is, the more severe the land damage is, and the less suitable the land is for reclamation. (c) Yield reduction caused by the damaged land (\%), which is denoted as $X_{3}$. This refers to the decrease in productivity due to land damage, mainly referring to the land loss due to excavation in the mining area, and the reduction of productivity due to waste deposit and building construction. Similarly, the greater the value of $X_{3}$, the more severe the damage to the land, and the less suitable the land for reclamation.

(2) The soil conditions are mainly considered in four aspects, namely, clay content $(\%) X_{4}$, organic matter content $(\%) X_{5}$, soil thickness before damage $(\mathrm{cm})$ $X_{6}$, and soil conservation rate available for land reclamation (\%) $X_{7}$.

(3) The original vegetation condition of the land reclamation units, that is, the vegetation coverage rate (\%) of the land reclamation units before mining, $X_{8}$. The more vegetation there is, the more the original ecological environment is conducive to vegetation growth, and the more favorable to land reclamation.

(4) Irrigation and drainage conditions: according to the requirements of the standards, the irrigation and drainage conditions of the land reclamation units must be considered. Due to the dry climate in Xinjiang, water resources are extremely scarce, and the surface basically does not retain water. For this reason, drainage conditions are not considered and only irrigation conditions are considered in the selection of indexes. That is, the surface river runoff which is available for irrigation in the land reclamation units $\left(\mathrm{m}^{3} / \mathrm{s}\right)$ is denoted as $X_{9}$.

\section{Suitability Evaluation Units of Mines Land Reclamation}

The evaluation unit is the basic physical unit for the suitability evaluation of land reclamation. The appropriateness of the evaluation unit has a direct effect on the quality of the land reclamation suitability evaluation, the size of the reclamation project, and the result of the reclamation. The nonmetallic mines in Xinjiang are mined in an open pit and the facilities of mines include open pits, waste rock yards, industrial squares, living quarters, blasting equipment storage areas, and landfills. Open-pit mining methods include side-hill cut mining and deep-concaved open-pit mining (Figure 2). For side-hill cut mining, the waste rocks cannot be backfilled, so that a high steep slope will be formed. The open pits formed in deep-concaved open-pit mining can be backfilled with waste rocks during or after the mining process, so the terrain is gentler. Hence, when dividing the open pits into land reclamation units, the open pits may be divided into just one land reclamation unit if the pits used deep-concaved open-pit mining. If the pits used side-hill cut mining, they would be divided into two reclamation units: an open-pit slope area and a flat bottom area, or they can be classified as one land reclamation unit of open mining slope area. If the mining method is a combination of side-hill cut mining and deep-concaved open-pit mining, then the open pit is divided into two land reclamation units: the open-pit slope area and the bottom pit mining area. The research conducted here is a study on 21 nonmetallic mines in Xinjiang, and the 21 mines are divided into 149 land reclamation units, as shown in Supplementary Table 1.

\section{Classification Results of Land Reclamation Suitability Evaluation}

\subsection{Factor Analysis}

4.1.1. Introduction of Factor Analysis. Factor analysis [33-35] is a linear function of the common factor and the special factor that each original variable plays a dominant role in the data of the sample, so as to better explain the correlation of the original variable and reduce its dimension. The basic idea of factor analysis is to group variables according to the size of correlation, so that the correlation between variables in the same group is higher, and the correlation between variables in different groups is lower. Each group of variables represents a basic structure, which is represented by an unobservable comprehensive variable called a common factor. Another function of factor analysis is to classify variables (or samples) [36].

4.1.2. Results of Factor Analysis. The factor analysis data are listed in Supplementary Table 1. The factor analysis extracted the factor by the principal factor standard, and the criterion was that the first $k$ principal factors were extracted when the cumulative contribution rate reached $85 \%$. The load matrix of the factor was rotated according to the Kaiser-standardized orthogonal rotation method. After analysis, it was concluded that the measured KMO value was 0.781 , the statistical value of the Bartlett spherical test was 1528.242, and the phase accompanying probability Sig. $=0.000<0.01$, indicating that the chosen variables were suitable for factor analysis. The calculation process of factor analysis was carried out by SPSS software. The results of specific factor analysis are shown in Tables 2 and 3.

It can be seen from Table 2 that the selection of three factors could explain $85.91 \%$ of the variance of the original variables (accumulated contribution rate), indicating that all nine indexes variables could be well explained by the three principal factors. A matrix of rotational components (Table 3 ) could be obtained by rotating the extracted principal component matrix. Table 3 shows that the variables represented by the rotated principal factors were obviously polarized. The principal factor 1 could be interpreted as soil and vegetation factors; it could also be interpreted as the original ecological environmental conditions of the land reclamation units. Principal factor 2 represented the severity of mining damage of the land, and principal factor 3 


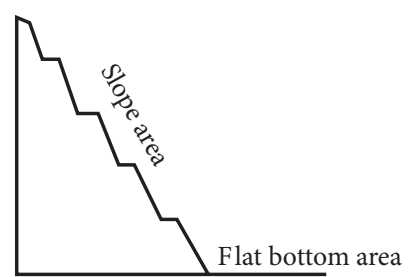

(a)

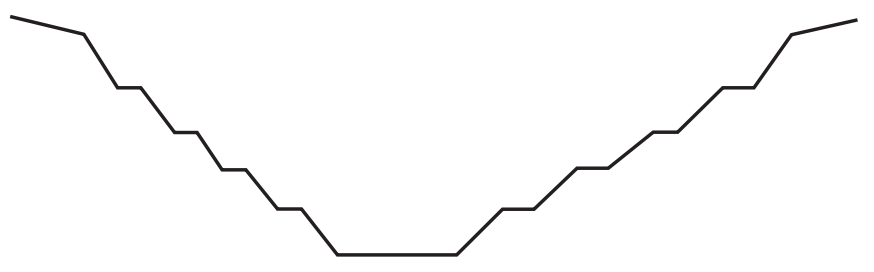

(b)

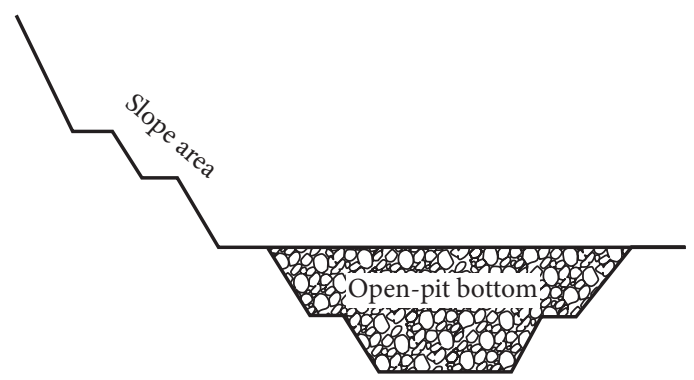

(c)

FIgURE 2: Open-pit mining methods for nonmetal mines in Xinjiang: (a) side-hill cut mining, (b) deep-concaved open-pit mining, (c) combination of side-hill cut mining, and deep-concaved open-pit mining.

TABle 2: Explanation of total variance.

\begin{tabular}{|c|c|c|c|c|c|c|c|c|c|}
\hline \multirow{2}{*}{ Component } & \multicolumn{3}{|c|}{ Initial characteristic values } & \multicolumn{3}{|c|}{ Load of extracted sum of squares } & \multicolumn{3}{|c|}{ Load of rotated sum of squares } \\
\hline & Total & Variance \% & Cumulative \% & Total & Variance \% & Cumulative \% & Total & Variance $\%$ & Cumulative $\%$ \\
\hline 1 & 5.112 & 56.796 & 56.796 & 5.112 & 56.796 & 56.796 & 4.278 & 47.530 & 47.530 \\
\hline 2 & 1.725 & 19.162 & 75.958 & 1.725 & 19.162 & 75.958 & 2.470 & 27.441 & 74.971 \\
\hline 3 & 0.895 & 9.950 & 85.907 & 0.895 & 9.950 & 85.907 & 0.984 & 10.936 & 85.907 \\
\hline 4 & 0.610 & 6.776 & 92.683 & & & & & & \\
\hline 5 & 0.305 & 3.384 & 96.067 & & & & & & \\
\hline 6 & 0.193 & 2.143 & 98.210 & & & & & & \\
\hline 7 & 0.079 & 0.880 & 99.090 & & & & & & \\
\hline 8 & 0.065 & 0.720 & 99.809 & & & & & & \\
\hline 9 & 0.017 & 0.191 & 100.000 & & & & & & \\
\hline
\end{tabular}

TABLE 3: Rotation component matrix.

\begin{tabular}{|c|c|c|c|}
\hline \multirow{2}{*}{ Original index variable } & \multicolumn{3}{|c|}{ Principal factors } \\
\hline & 1 & 2 & 3 \\
\hline Dominant slope of the surface after excavation or the deposition of debris $\left({ }^{\circ}\right), X_{1}$ & -0.235 & 0.886 & -0.040 \\
\hline Depth of the excavation $(\mathrm{m})$ or the flatness of the deposited debris $\left(\mathrm{m}^{3} / \mathrm{m}^{2}\right), X_{2}$ & -0.076 & 0.794 & -0.140 \\
\hline Yield reduction caused by the damaged land (\%), $X_{3}$ & -0.340 & 0.802 & 0.145 \\
\hline Clay content in soil (\%), $X_{4}$ & 0.965 & -0.050 & 0.015 \\
\hline Organic matter content in soil (\%), $X_{5}$ & 0.943 & 0.054 & -0.096 \\
\hline Soil thickness before land damage $(\mathrm{cm}), X_{6}$ & 0.867 & -0.353 & 0.068 \\
\hline Soil conservation rate available for reclamation (\%), $X_{7}$ & 0.744 & -0.497 & 0.142 \\
\hline Vegetation coverage rate of land reclamation units before mining (\%), $X_{8}$ & 0.937 & -0.134 & 0.202 \\
\hline Surface river runoff available for irrigation in land reclamation units $\left(\mathrm{m}^{3} / \mathrm{s}\right), X_{9}$ & 0.310 & -0.127 & 0.931 \\
\hline
\end{tabular}

represented the irrigation conditions. The three principal factors were consistent with the classification results of evaluation indexes, which showed that the selection of evaluation indexes was reasonable. The individual scores of the three principal factors (Supplementary Table 2) were calculated by SPSS software [37]. The composite score was equal to the individual scores of the three principal factors multiplied by the corresponding variance percentage. The degree of suitability for land reclamation (Supplementary
Table 2) could be assessed from the magnitude of the composite score.

\subsection{Cluster Analysis}

4.2.1. Introduction of Cluster Analysis. Cluster analysis [38] is a statistical method for studying classification problem with the principle of multivariate statistical analysis. The idea 
of this method is to consider all samples as one class and then define the distance between classes. The two classes with the closest selectivity (e.g., the smallest distance) are merged into a new class. Then the distance between the new class and other classes is calculated, and then the two classes with the closest distance are merged, so that one class is reduced until all samples are merged into one class [36].

4.2.2. Results of Cluster Analysis. In cluster analysis, merging of categories is done using the average distance between categories and the distance between categories is measured by the square of the Euclidean distance. The calculation process of cluster analysis is carried out by SPSS software [37]. Figure 3 is the cluster analysis spectrum (tree diagram) and displays intuitively the gradual process of merging samples. A total of 148 steps were performed in this cluster. The land reclamation units No. 147 and No. 148 were clustered first which in turn was clustered with No. 149, and so the process went on. Finally, after 148 steps of clustering, 149 samples were grouped into one large category.

Figure 3 shows that it was most desirable to classify the 149 land reclamation units into five categories. In order to be consistent with the classification results from regulations and standards (Table 1), the land reclamation suitability evaluation results were also classified into four categories. Since the cluster analysis merely classifies the samples, the classification of the land reclamation suitability evaluation results must be done in combination with the composite scores from factor analysis (Supplementary Table 2). For the seven land reclamation units (unit designations 1 7) of the limestone mine in the Aktas mining area in Chabuchar County, Xinjiang, category " 1 " has the highest composite score, and category " 4 " has the lowest composite score. According to the composite scores of the land reclamation units, categories IV and V of the cluster analysis were finally combined into one category. The results of land reclamation suitability evaluation are shown in Figure 3 and Supplementary Table 2. The results in Supplementary Table 2 show that the evaluation results using combined cluster and factor analysis were consistent with and more accurate than the standard classification results. Such evaluation results were more conducive to guiding the later stage of the land reclamation work.

4.3. Analysis of Classification Results. Through statistical analysis of the land reclamation suitability results of the above 149 land reclamation units, 46 land reclamation units had a reclamation suitability of " 4 ," which were unsuitable. The land reclamation direction was bare land, and the limiting factors of reclamation included extremely severe damage to the land, no irrigation conditions, poor soil quality, and undeveloped vegetation on the original surface. There were 35 land reclamation units whose reclamation suitability was " 3 ," which was not very suitable. The restrictions on land reclamation for these units included severe damage to the land, poor soil quality on the surface, and little

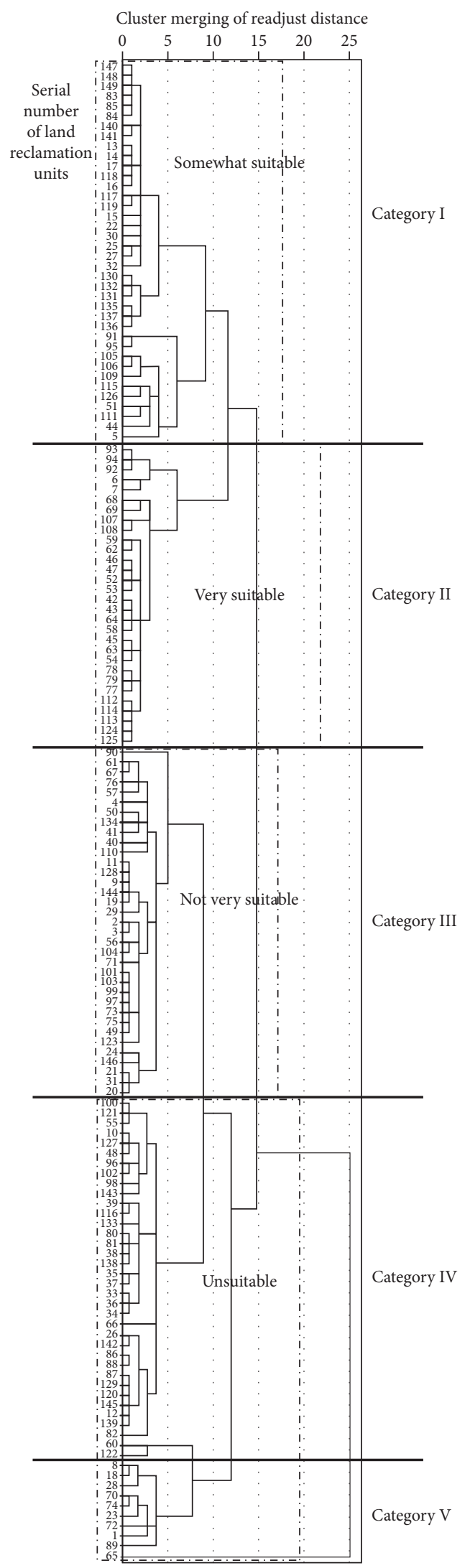

FIGURE 3: Dendrogram of clustering analysis using average linkage (between groups). 
vegetation on the surface. For land reclamation units with a suitability level of "very suitable" or "somewhat suitable," the severity of land damage was generally light, the soil quality was also good, the surface vegetation was well developed, and the irrigation conditions were sufficient.

4.4. Analysis of Selected Evaluation Indexes. In order to analyze the correlation between the nine selected evaluation indexes and the land reclamation suitability level, the average of the nine classification indexes of 149 land reclamation units divided into 4 categories was calculated (Table 4 and Figure 4). Table 4 and Figure 4 show that, among the nine classification indexes, three indexes values $\left(X_{1} \sim X_{3}\right)$ gradually increased as the suitability of land reclamation became worse, and the values of the remaining six indexes gradually decreased as the suitability of land reclamation became worse. The changing behavior of the index values was consistent with factor analysis results and agreed with the actual situation of the land reclamation work. The selection of the nine classification indexes was reasonable.

\section{Land Reclamation Suitability Evaluation Model}

5.1. Establishment of Evaluation Model. The land reclamation suitability evaluation model described here adopted the Fisher discriminant analysis method. Fisher discriminant analysis method [39] is to establish a scientific classification rule, i.e., discriminant rule, to classify any new observation sample according to the known characteristics. The basic idea of Fisher discriminant is projection, which projects $k$ group $m$ metadata to a certain direction, so that the postprojection group and the group can be opened as far as possible. Then, the appropriate discriminant rules are selected to classify and discriminate the new samples.

According to the principle and calculation steps of Fisher discriminant analysis method, nine evaluation indexes were used as independent variables of the discriminant analysis, and the suitability categories determined by combined cluster analysis and factor analysis were used as a grouping variable. The data of Supplementary Table 1 were analyzed using SPSS analysis software [37], and the land reclamation suitability evaluation model of nonmetallic mines reclamation in Xinjiang was established. The coefficients of the discriminant function were obtained, as shown in Table 5.

Using the coefficients of the Fisher discriminant function given in Table 5, the following three linear discriminant function expressions could be established:

$$
\begin{aligned}
y_{1}= & 0.046 X_{1}-0.007 X_{2}+0.059 X_{3}-0.005 X_{4}+0.274 X_{5} \\
& -0.058 X_{6}-0.061 X_{7}-0.006 X_{8}-0.009 X_{9}-1.791 \\
y_{2}= & 0.112 X_{1}+0.004 X_{2}-0.055 X_{3}-0.488 X_{4}+0.562 X_{5} \\
& +0.002 X_{6}+0.003 X_{7}+0.026 X_{8}-0.233 X_{9}+0.98 \\
y_{3}= & 0.005 X_{1}+0.006 X_{2}+0.036 X_{3}+0.07 X_{4}-0.402 X_{5} \\
& +0.057 X_{6}+0.028 X_{7}-0.023 X_{8}+0.116 X_{9}-3.677
\end{aligned}
$$

The above three linear discriminant functions were three independent calculation formulas. The values of the corresponding sample functions could be calculated using functional formulas. To determine which group a new sample should belong to, the samples function values of the mines evaluation units were compared with the squared distance of the central value (Table 6) of the four classification groups. The sample belonged to the group which had the least squared distance.

5.2. Testing of Evaluation Model. According to the established Fisher discriminant model, the 149 land reclamation units were tested using a backward substitution estimation method. Only two misclassified samples appeared in the analysis, the correct rate was $98.7 \%$, and the two misclassified land reclamation units were No. 12 and No. 139. According to the classification, No. 12 is the waste rock yard of the Dolomite Mine of Tianhu No. 1 in Hami City, Xinjiang, and No. 139 is the waste rock dumping site of the vermiculite mine of $32 \mathrm{nd}$ regimen. The classification result was " 3 " or " 4 " from relevant regulations and standards; according to the combined analysis of factors and clusters, the result was " 4 ." In terms of the severity of land damage, the land reclamation suitability should be " 3 ." However, from the viewpoint of irrigation conditions, the original vegetation development, and the soil quality, it is difficult to reclaim it into grassland. The land reclamation suitability rating is " 4 ." Figure 5 shows that level " 3 " and " 4 " samples are poorly clustered with the central points, with a poorly defined boundary. As a result, some of the samples are subject to misclassification.

5.3. Application of Evaluation Model. Using the land reclamation suitability evaluation model established above, the land reclamation units of the Toga Solo limestone mine in Dabancheng, Urumqi, were evaluated for land reclamation suitability. The limestone mine had an area of $1.5576 \mathrm{~km}^{2}$, with a total of 5 ore bodies. Among them, the No. 2 and No. 5 ore bodies adopted the side-hill cut mining, and the No.1, No. 3, and No. 4 ore bodies adopted the side-hill cut mining and deep-concaved open-pit mining method. The evaluation divided the entire mining area into 15 land reclamation units (Figure 6). The specifically measured indexes of each land reclamation unit are shown in Table 7.

The indexes values of the 15 land reclamation units in Table 7 were substituted, respectively, into three discriminant formula, and each land reclamation unit can obtain three discriminant function values. The squared distance from the discriminant function value to the central value of each category was calculated for each evaluation unit and compared. The results are shown in Table 8 . It could be seen from Table 8 that the classification results of the land reclamation suitability of the 15 land reclamation units were consistent with the classification results from regulations and standards. Furthermore, the classification results were unique, the conclusions were more accurate, and the classification could more favorably guide the task of reclaiming the mine land. 
TABLE 4: Comparison of classification indexes for different land reclamation suitability categories.

\begin{tabular}{lccccccccc}
\hline \multirow{2}{*}{ Land reclamation suitability categories } & \multicolumn{9}{c}{ Average of indexes } \\
& $X_{1}$ & $X_{2}$ & $X_{3}$ & $X_{4}$ & $X_{5}$ & $X_{6}$ & $X_{7}$ & $X_{8}$ & $X_{9}$ \\
\hline 1 & 3.23 & 0.40 & 12.77 & 6.19 & 3.02 & 47.17 & 100.00 & 32.33 & 0.59 \\
2 & 9.63 & 1.22 & 30.55 & 3.32 & 1.51 & 16.76 & 34.55 & 14.61 & 0.14 \\
3 & 15.80 & 6.21 & 91.29 & 2.53 & 1.13 & 8.17 & 19.57 & 10.09 & 0.40 \\
4 & 50.87 & 55.26 & 94.78 & 1.12 & 0.53 & 2.98 & 0.87 & 5.28 & 0.01 \\
\hline
\end{tabular}

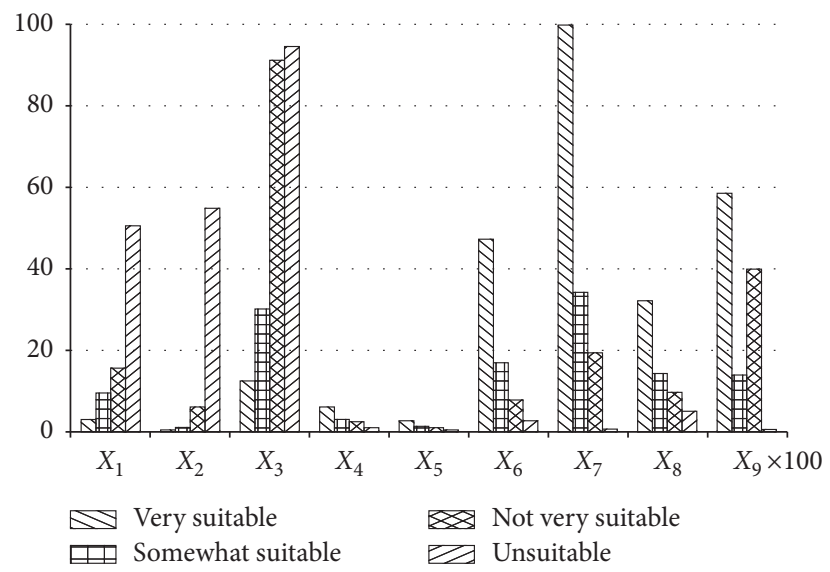

FIgURE 4: Bar graph showing the indexes values for four categories of land reclamation suitability.

Table 5: Coefficients of Fisher discriminant function.

\begin{tabular}{lccc}
\hline Evaluation index & \multicolumn{2}{c}{ Function } & $y_{2}$ \\
& $y_{1}$ & 0.112 & 0.005 \\
$X_{1}$ & 0.046 & 0.004 & 0.006 \\
$X_{2}$ & -0.007 & -0.055 & 0.036 \\
$X_{3}$ & 0.059 & -0.488 & 0.070 \\
$X_{4}$ & -0.005 & 0.562 & -0.402 \\
$X_{5}$ & 0.274 & 0.002 & 0.057 \\
$X_{6}$ & -0.058 & 0.003 & 0.028 \\
$X_{7}$ & -0.061 & 0.026 & -0.023 \\
$X_{8}$ & -0.006 & -0.233 & 0.116 \\
$X_{9}$ & -0.009 & 0.980 & -3.677 \\
(Constants) & -1.791 & & \\
\hline
\end{tabular}

TABLE 6: Central values of typical discriminant function for the four suitability classes.

\begin{tabular}{lccc}
\hline Evaluation results for reclamation units & \multicolumn{2}{c}{ Function } & $y_{2}$ \\
& $y_{1}$ & 0.492 & 0.816 \\
Very suitable "1" & -9.093 & 0.122 & -1.291 \\
Somewhat suitable "2" & -2.307 & -2.607 & 0.305 \\
Not very suitable "3" & 2.865 & 1.562 & 0.303 \\
Unsuitable "4" & 5.656 & & \\
\hline
\end{tabular}




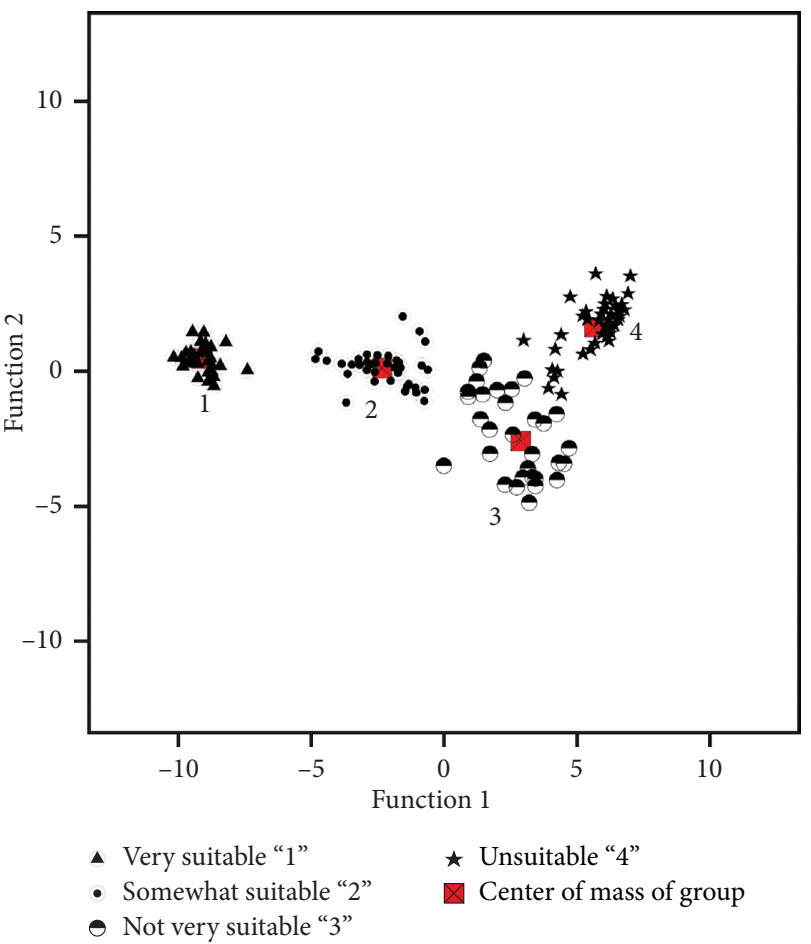

FIGURE 5: Schematic diagram of distance distribution for different classes of samples and different central points.

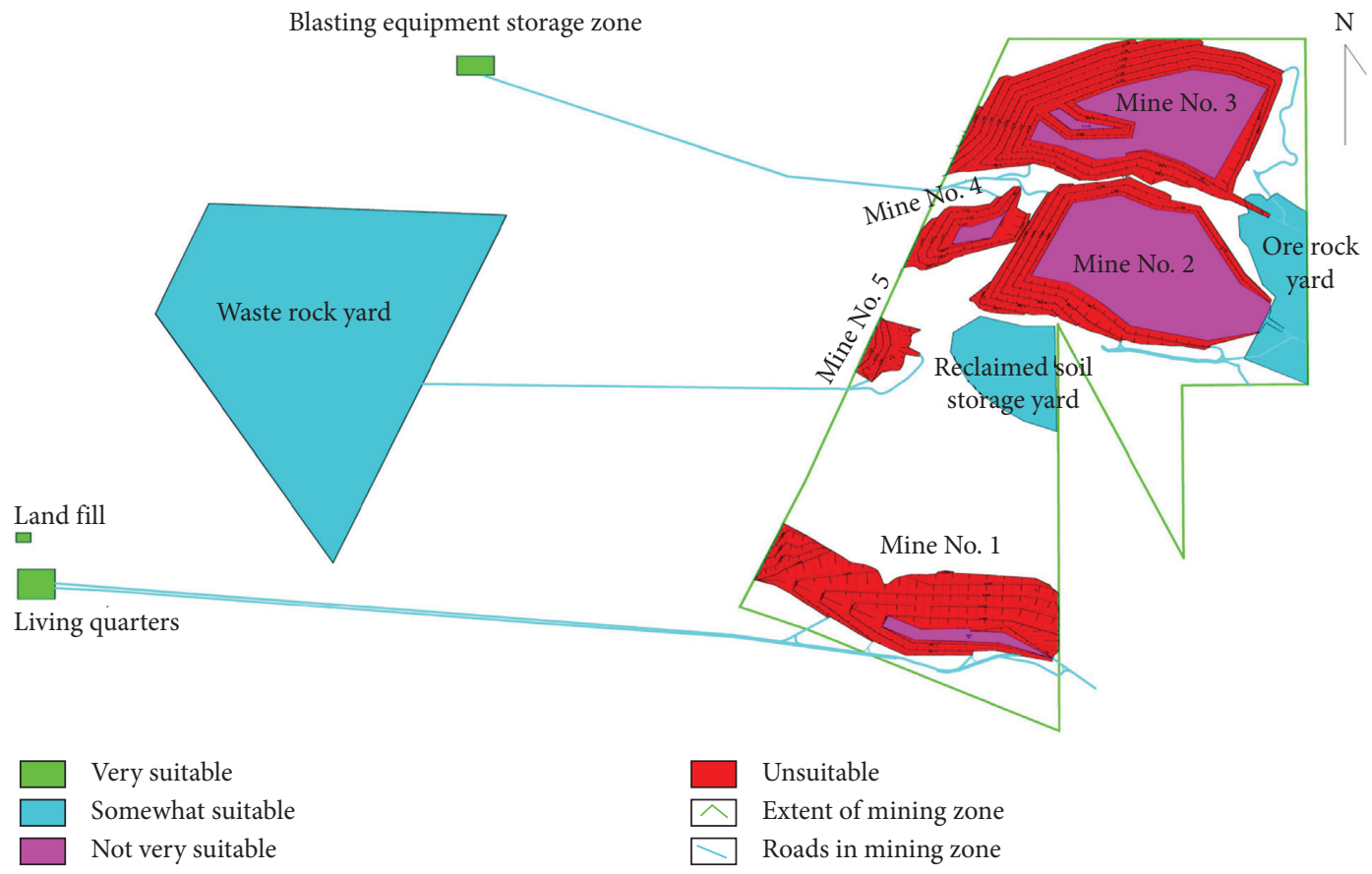

Figure 6: Schematic diagram of land reclamation suitability evaluation for limestone mine at Dabancheng Toga Solo in Urumqi. 
TABLE 7: Actual measured index values for various land reclamation units.

\begin{tabular}{|c|c|c|c|c|c|c|c|c|c|c|c|}
\hline $\begin{array}{l}\text { Serial } \\
\text { no. }\end{array}$ & Mine & Unit evaluated & $X_{1}$ & $X_{2}$ & $X_{3}$ & $X_{4}$ & $X_{5}$ & $X_{6}$ & $X_{7}$ & $X_{8}$ & $X_{9}$ \\
\hline 1 & & No. 1 slope region of open-pit & 50 & 80 & 100 & 1.8 & 0.6 & 2 & 0 & 5 & 0 \\
\hline 2 & & $\begin{array}{c}\text { Deep-concaved open-pit mining part } \\
\text { of No. } 1\end{array}$ & 10 & 0 & 100 & 1.8 & 0.6 & 2 & 4 & 5 & 0.366 \\
\hline 3 & & No. 2 slope region of open-pit & 50 & 100 & 100 & 1.8 & 0.6 & 2 & 0 & 5 & 0 \\
\hline 4 & & Flat region at bottom of No. 2 & 5 & 0 & 100 & 1.8 & 0.6 & 2 & 4 & 5 & 0.366 \\
\hline 5 & & No. 3 slope region of open-pit & 50 & 160 & 100 & 1.8 & 0.6 & 2 & 0 & 5 & 0 \\
\hline 6 & & $\begin{array}{c}\text { Deep-concaved open-pit mining part } \\
\text { of No. } 3\end{array}$ & 8 & 0 & 100 & 1.8 & 0.6 & 2 & 4 & 5 & 0.366 \\
\hline 7 & Toga solo limestone mine in Dabancheng, & No. 4 slope region of open-pit & 50 & 60 & 100 & 1.8 & 0.6 & 2 & 0 & 5 & 0 \\
\hline 8 & Urumqi & $\begin{array}{c}\text { Deep-concaved open-pit mining part } \\
\text { of No. } 4\end{array}$ & 10 & 0 & 100 & 1.8 & 0.6 & 2 & 4 & 5 & 0.366 \\
\hline 9 & & No. 5 slope region of open-pit & 50 & 60 & 100 & 1.8 & 0.6 & 2 & 0 & 5 & 0 \\
\hline 10 & & Waste rock dumping site & 30 & 18 & 85 & 3.4 & 2.16 & 20 & 80 & 15 & 0.366 \\
\hline 11 & & Reclaimed soil storage yard & 30 & 12 & 60 & 4.2 & 2.34 & 30 & 100 & 20 & 0.366 \\
\hline 12 & & Living quarters & 2 & 0 & 5 & 4.2 & 2.34 & 45 & 100 & 20 & 0.366 \\
\hline 13 & & Blasting equipment storage & 5 & 0 & 10 & 4.2 & 2.34 & 45 & 100 & 20 & 0.366 \\
\hline 14 & & Ore rock yard & 30 & 8 & 90 & 3.4 & 2.16 & 20 & 80 & 20 & 0.366 \\
\hline 15 & & Landfill & 3 & 0 & 20 & 4.2 & 2.34 & 35 & 100 & 20 & 0.366 \\
\hline
\end{tabular}

Note. Data came from field survey measurements, relevant tests, land reclamation reports of this mine, environmental assessment reports, reports on mining geology, mining resources development and utilization plans, and mining geological environmental protection plans.

TABLE 8: Evaluation results of land reclamation units.

\begin{tabular}{|c|c|c|c|c|c|c|c|c|c|}
\hline \multirow{2}{*}{$\begin{array}{l}\text { Sample serial } \\
\text { no. }\end{array}$} & \multicolumn{3}{|c|}{$\begin{array}{c}\text { Values of } \\
\text { discriminant function }\end{array}$} & \multirow{2}{*}{$d_{1}^{2}$} & \multirow[t]{2}{*}{$d_{2}^{2}$} & \multirow{2}{*}{$d_{3}^{2}$} & \multirow{2}{*}{$d_{4}^{2}$} & \multirow{2}{*}{$\begin{array}{l}\text { Evaluation results from } \\
\text { model }\end{array}$} & \multirow{2}{*}{$\begin{array}{c}\text { Evaluation results from regulations } \\
\text { and standards }\end{array}$} \\
\hline & $y_{1}$ & $y_{2}$ & $y_{3}$ & & & & & & \\
\hline 1 & 5.880 & 0.964 & 0.592 & 224.461 & 71.272 & 21.923 & 0.491 & 4 & 3 or 4 \\
\hline 2 & 4.349 & -3.901 & 0.045 & 200.579 & 62.264 & 3.942 & 31.617 & 3 & 3 or 4 \\
\hline 3 & 5.740 & 1.037 & 0.719 & 220.338 & 69.634 & 21.722 & 0.456 & 4 & 3 or 4 \\
\hline 4 & 4.118 & -4.463 & 0.021 & 199.734 & 64.029 & 5.095 & 38.745 & 3 & 3 or 4 \\
\hline 5 & 5.322 & 1.258 & 1.102 & 208.461 & 65.216 & 21.615 & 0.844 & 4 & 3 or 4 \\
\hline 6 & 4.256 & -4.126 & 0.035 & 200.152 & 62.881 & 4.314 & 34.379 & 3 & 3 or 4 \\
\hline 7 & 6.019 & 0.890 & 0.464 & 228.667 & 72.992 & 22.206 & 0.609 & 4 & 3 or 4 \\
\hline 8 & 4.349 & -3.901 & 0.045 & 200.579 & 62.264 & 3.942 & 31.617 & 3 & 3 or 4 \\
\hline 9 & 6.019 & 0.890 & 0.464 & 228.667 & 72.992 & 22.206 & 0.609 & 4 & 3 or 4 \\
\hline 10 & -1.043 & -0.088 & 2.101 & 66.797 & 13.147 & 24.842 & 50.837 & 2 & 2 or 3 \\
\hline 11 & -4.258 & 1.208 & 2.147 & 25.669 & 16.808 & 68.682 & 101.816 & 2 & 2 or 3 \\
\hline 12 & -9.584 & 1.093 & 0.789 & 0.602 & 58.224 & 168.895 & 232.720 & 1 & 1 \\
\hline 13 & -9.150 & 1.154 & 0.985 & 0.470 & 53.073 & 158.963 & 219.859 & 1 & 1 \\
\hline 14 & -0.707 & -0.271 & 2.106 & 72.580 & 14.255 & 21.462 & 47.100 & 2 & 2 or 3 \\
\hline 15 & -8.072 & 0.351 & 0.772 & 1.064 & 37.551 & 128.596 & 190.168 & 1 & 1 \\
\hline
\end{tabular}

\section{Conclusions}

(1) In this work, the evaluation indexes system of land reclamation suitability evaluation for nonmetallic mines in Xinjiang was established. The evaluation indexes fit the actual situation of nonmetallic mines in Xinjiang [21, 22]. They have included the factors affecting the suitability of land reclamation and the direction of land reclamation to the greatest extent possible. The evaluation results are highly consistent with the actual situation and the analysis of the classification indexes data showed that all nine indexes selected have affected the land reclamation suitability evaluation results to varying degrees.
(2) According to the mining mode of nonmetallic mines and the layout of mine facilities, the mines are reasonably divided into several land reclamation units. For open pits mined with the side-hill cut mining method, the pits are divided into the slope region and the bottom flat area. Open pits mined with deepconcaved open-pit mining method are divided into just one open-pit mining area. Open pits mined with the combined side-hill cut and deep-concaved openpit mining method are divided into slope region and deep-concaved open-pit mining part.

(3) The 149 land reclamation units are classified into 4 categories using a combination of factor analysis and cluster analysis. The classification results are 
compared with that obtained using the regulations and standards; the comparison showed that the classification was unique and consistent with the regulations and standards.

(4) In the evaluation model established here, all nine indexes can be obtained quantitatively through actual measurement, experiment, and relevant reports, without resorting to weight factors and humanassigned values $[6-8,27,28]$. It avoided the effects of human factors on the results of the evaluation model. In actual application of the evaluation model, it is only necessary to collect the relevant classification indexes data.

(5) In this work, the discriminant analysis method was applied to the suitability evaluation of land reclamation for mines, and a land reclamation suitability evaluation model was established for land reclamation of nonmetallic mines in Xinjiang. The model was tested and the results of real case calculation proved that the calculation process of the discriminant analysis method was simple to implement and the model structure was stable. The model was shown to have superior discrimination capability for suitability evaluation results of mines reclamation and the evaluation model may serve as a useful reference in the effort of reclaiming for nonmetallic mines in Xinjiang.

(6) The biggest difference between the classification results of this model and standard classification results is to distinguish the classification of "not very suitable" and "unsuitable," which is often the most critical difference affecting the mines land reclamation direction in Xinjiang.

(7) The model is established on the basis of analyzing 149 land reclamation units in 21 mines. It is representative, but it still has certain limitations due to the limited samples. In future work, the evaluation model may be further refined by including even more representative nonmetallic mines.

\section{Data Availability}

The data used to support the findings of this study are included within the article.

\section{Conflicts of Interest}

The authors declare that they have no conflicts of interest.

\section{Acknowledgments}

This research was funded by the Natural Science Foundation of Xinjiang (grant no. 2018D01C061).

\section{Supplementary Materials}

Samples of suitability evaluation of nonmetallic mine land reclamation in Xinjiang. (Supplementary Materials)

\section{References}

[1] Y. J. Pu, H. S. Yang, X. P. Wang, and X. L. Peng, "The development direction of Xinjiang nonmetallic ming: green ming," China Non-metallic Minerals Industry, no. 2, pp. 3-4, 2014.

[2] S. J. Zhang, H. D. Xia, G. Y. Ji, L. Shang, and G. Y. Liu, "Analysis on formation regulating and looking for the mine potential of non-metal mineral resources in Xinjiang," China Non-Metallic Minerals Industry, vol. 6, pp. 38-42+60, 2015.

[3] Q. Zeng, G. S. Li, J. X. Dong, and Y. Pu, "Typical ecological and environmental issues and countermeasures in coal mining in Xinjiang region," Mining Safety \& Environmental Protection, vol. 44, no. 1, pp. 106-110, 2017.

[4] Z. Z. Zhang, W. M. Guan, J. H. Zhu, T. S. Zhou, and Q. Xian, "Establishment and application of the suitability evaluation model for reclamation of grassland of Xinjiang coal mine," China Mining Magazine, vol. 25, no. 2, pp. 72-78+93, 2016.

[5] H. Wang, P. Wang, and L. X. Xie, "Commentary on methods for suitability evaluation of land reclamation," Journal of Central South University of Forestry \& Technology, vol. 30, no. 4, pp. 154-158, 2010.

[6] S. M. Moosavirad and B. Behnia, "Retracted article: suitability evaluation for land reclamation in mining areas: gol-e-gohar iron ore mine of sirjan, Kerman, Iran," International Journal of Mining, Reclamation and Environment, vol. 31, no. 1, pp. 38-51, 2017.

[7] D. Shi, "Land reclamation suitability evaluation based on the limit method," Applied Mechanics \& Materials, vol. 253, pp. 1069-1074, 2013.

[8] S. D. Wang, Z. Guo, Q. J. Chen, and H. B. Zhang, "Study and application of suitability evaluation of land reclamation based on comprehensive extreme condition method," Science of Surveying \& Mapping, vol. 37, no. 1, pp. 66-70, 2012.

[9] J. M. C. Pereira and L. Duckstein, "A multiple criteria decision-making approach to GIS-based land suitability evaluation," International Journal of Geographical Information Systems, vol. 7, no. 5, pp. 407-424, 1993.

[10] S. Kalogirou, "Expert systems and GIS: an application of land suitability evaluation," Computers, Environment and Urban Systems, vol. 26, no. 2-3, pp. 89-112, 2002.

[11] T. V. Reshmidevi, T. I. Eldho, and R. Jana, "A GIS-integrated fuzzy rule-based inference system for land suitability evaluation in agricultural watersheds," Agricultural Systems, vol. 101, no. 1-2, pp. 101-109, 2009.

[12] A. Kodir, D. M. Hartono, H. Haeruman, and I. Mansur, "Integrated post mining landscape for sustainable land use: a case study in South Sumatera, Indonesia," Sustainable Environment Research, vol. 27, no. 4, pp. 203-213, 2017.

[13] B. Ye, "Integrating MCE with GIS for suitability evaluation of the reclamation land in Antaibao open pit coal mine," World Automation Congress, pp. 1-5, 2012.

[14] D. C. Fang, G. L. Liu, F. Wang, and L. P. Zhang, "The research on the GIS-based land suitability evaluation model (LSEM)," Geomatics \& Spatial Information Technology, vol. 1, pp. 35-36, 2004.

[15] D. B. Yang, W. X. Zhang, and Q. Yao, "Research of mining subsided land reclamation system based on GIS," Applied Mechanics \& Materials, vol. 130, pp. 1858-1861, 2012.

[16] A. Zhang and H. Zhang, "GIS-based coal mining land reclamation suitability evaluation assessment," in Proceedings of the 2011 19th International Conference on Geoinformatics, pp. 1-4, Shanghai, China, June 2011. 
[17] S. M. Kim, J. Suh, S. Oh et al., "Assessing and prioritizing environmental hazards associated with abandoned mines in Gangwon-do, South Korea: the Total Mine Hazards Index," Environmental Earth Sciences, vol. 75, no. 5, p. 369, 2016.

[18] F. Amiri and A. R. B. M. Shariff, "Application of geographic information systems in land-use suitability evaluation for beekeeping: a case study of Vahregan watershed (Iran)," African Journal of Agricultural Research, vol. 7, no. 1, pp. 89-97, 2012.

[19] Z. Z. Zhang, R. Q. Guo, T. S. Zhou, T. S. Zhou, and Q. Xian, "Suitability evaluation method and application for land reclamation to grassland in Xinjiang coal mines," Transactions of the Chinese Society of Agricultural Engineering (Transactions of the CSAE), vol. 31, no. 11, pp. 278-286, 2015.

[20] G. L. Wang, W. C. Zhang, K. S. Song, Q. F. Hu, and H. C. Luo, "Suitability evaluation for land reclamation in coal mining subsidence area based on extenics," Chinese Journal of Underground Space \& Engineering, vol. 11, no. 1, pp. 222-228, 2015.

[21] H. L. Yu, X. Q. Li, C. X. Deng, and N. Lu, “The reclaimed land suitability evaluation and reclamation mode of coal mine area in five mountains mountain," Journal of Agriculture, vol. 2, no. 6, pp. 59-64, 2012.

[22] X. S. Tian, C. R. Zhou, J. B. Zheng, and X. L. Tan, "Research on suitability evaluation of the gas temporary land based on the index method," Environmental Engineering, vol. 32, no. s1, pp. 856-859, 2014.

[23] R. T. Bi, Z. K. Bai, H. Li, H. B. Shao, W. X. Li, and B. Y. Ye, "Establishing a clean-quality indicator system for evaluating reclaimed land in the antaibao opencast mine area, China," Clean-oil, Air, Water, vol. 38, no. 8, pp. 719-725, 2010.

[24] M. Elaalem, A. Comber, and P. Fisher, "A comparison of fuzzy AHP and ideal point methods for evaluating land suitability," Transactions in GIS, vol. 15, no. 3, pp. 329-346, 2011.

[25] H. Y. Zhang, T. Sun, D. D. Shao, and W. Yang, "Fuzzy logic method for evaluating habitat suitability in an estuary affected by land reclamation,"Wetlands, vol. 36, no. 1, pp. 19-30, 2016.

[26] Y. Zhang, Q. Liu, and B. Q. Wu, "Study of land suitability evaluation based on the method of fuzzy clustering," Journal of Sichuan University of Science \& Engineering, vol. 26, no. 5, pp. 96-100, 2013.

[27] Q. J. Zhang and J. N. Lu, "Suitability evaluation on land reclamation in hebei fanshan phosphate mine," Advanced Materials Research, vol. 1010-1012, pp. 1291-1296, 2014.

[28] M. Yavuz and B. L. Altay, "Reclamation project selection using fuzzy decision-making methods," Environmental Earth Sciences, vol. 73, no. 10, pp. 6167-6179, 2015.

[29] H. B. Zhang, Z. Q. Hu, Q. J. Chen, H. Q. Xie, and C. H. Liu, "Application of artificial neural network technology in land reclamation of mining area," Journal of Liaoning Technical University, vol. 24, no. 1, pp. 26-28, 2005.

[30] F. Pavloudakis, M. Galetakis, and C. Roumpos, "A spatial decision support system for the optimal environmental reclamation of open-pit coal mines in Greece," International Journal of Mining, Reclamation and Environment, vol. 23, no. 4, pp. 291-303, 2009.

[31] Ministry of Land and Resources of the People's Republic of China, Completion Standards on Land Reclamation Quality, TD/T1036-2013, Ministry of Land and Resources of the People's Republic of China, Beijing, China, 2013.

[32] Ministry of Land and Resources of the People's Republic of China, Regulation on Compiling Land Reclamation Plan, TD/ T1031.1-2011, Ministry of Land and Resources of the People's Republic of China, Beijing, China, 2011.
[33] S. Ayoubi, F. Khormali, and K. L. Sahrawat, "Relationships of barley biomass and grain yields to soil properties within a field in the arid region: use of factor analysis," Acta Agriculturae Scandinavica, Section B-Plant Soil Science, vol. 59, no. 2, pp. 107-117, 2009.

[34] S. Ayoubi, F. Khormali, K. L. Sahrawat, and A. Claudia Rodrigues de Lima, “"Assessment of soil quality indicators related to land use change in a loessial soil using factor analysis in Golestan province", northern Iran," Journal of Agricultural Science and Technology, vol. 13, pp. 727-742, 2011.

[35] M. Taghipour, S. Ayoubi, and H. Khademi, "Contribution of lithologic and anthropogenic factors to surface soil heavy metals in western Iran using multivariate geostatistical analyses," Soil and Sediment Contamination: An International Journal, vol. 20, no. 8, pp. 921-937, 2011.

[36] D. J. Xiang, H. W. Li, and X. Y. Liu, Applied Multivariate Statistical analysis, China University of Geosciences Press, Beijing, China, 2005.

[37] L. B. Wang and G. T. Gu, Multivate Statistical Analysis: Models, Case Study and Application of SPSS, Economic Science Press, Beijing, China, 2010.

[38] M. Zeraatpisheh, S. Ayoubi, C. W. Brungard, and P. A. Finke, "Disaggregating and updating a legacy soil map using DSMART, fuzzy c-means and k-means clustering algorithms in central Iran," Geoderma, vol. 340, pp. 249-258, 2019.

[39] Z. F. Yuan and J. Y. Zhou, Multivariate Statistical Analysis, Science Press, Beijing, China, 2002. 